\title{
Gramática, ensino de língua portuguesa e formação do professor
}

\author{
Sandoval Nonato*
}

\section{Resumo}

Este estudo propõe discutir o estatuto da gramática como componente curricular da disciplina língua portuguesa na escola brasileira. Para tanto, apresenta, inicialmente, um panorama dos modos como a gramática escolar emerge no percurso histórico de constituição do ensino de língua portuguesa. Em seguida, contrasta esse estatuto historicamente construído com práticas de ensino de língua portuguesa atuais mediadas por estudantes de licenciatura em Letras, por ocasião de realização de estágio em escolas da rede pública da cidade de São Paulo (Brasil). A descrição e a análise do processo de implementação de um projeto de ensino sobre o funcionamento do verbo no texto poético, por um estudante, conforme registrado em seu relatório de estágio, permitem problematizar alguns desafios que a abordagem da gramática coloca para as práticas de ensino e para a formação do professor de língua portuguesa.

Palavras-chave: Ensino de língua portuguesa. Formação docente. Gramática escolar.

\footnotetext{
Faculdade de Educação da Universidade de São Paulo (FEUSP). Professor do Departamento de Metodologia de Ensino e Educação Comparada. Doutorado em Linguística (Universidade Estadual de Campinas, 2004). Estágio pós-doutoral em Didática de Línguas (Universidade de Genebra, 2006). Experiência em Linguística Aplicada, Linguística Textual e EnsinoAprendizagem (Métodos e Técnicas de Ensino). Pesquisa: formação e trabalho do professor de língua portuguesa e produção e recepção de gêneros textuais na escola. https://orcid.org/0000-0002-3976-584X .
} 


\section{Schooling grammar, teaching Portuguese language and teacher training Abstract}

This study proposes to discuss the status of schooling grammar as a curricular component of the subject Portuguese language in the Brazilian school. Therefore, it presents, initially, an overview of the ways in which schooling grammar is approached in the historical course of the constitution of Portuguese language teaching. Next, this historically constructed status of schooling grammar is contrasted with current Portuguese language teaching practices mediated by students for licentiate in Letters, on the occasion of an internship in schools of the public system of the city of São Paulo (Brazil). The description and analysis of the process of implementation of a teaching project about functioning of the verb in the poetic text by a student, as recorded in your internship report, allow us to problematize some of the challenges that the schooling grammar approach poses to teaching practices and to the training of the Portuguese language teacher.

Keywords: Schooling Gramar. Teacher training. Teaching Portuguese language.

Recebido em: 22/08/2020 // Aceito em: 24/02/2021. 


\section{Introdução}

O processo de descrição das línguas naturais ou gramatização consiste em um exercício de reflexão e um esforço de objetivação de longa duração, um trabalho histórico que Auroux (1992) qualifica como uma "revolução tecnológica" comparada a grandes descobertas científicas, tais como a teoria heliocêntrica de Copérnico ou as leis de Newton, que "conduz a produzir dicionários e gramáticas de todas as línguas do mundo (e não somente dos vernáculos europeus) na base da tradição greco-latina". (AUROUX, 1992, p. 8). O duradouro trabalho de produção de um saber linguístico suposto nos processos de gramatização só se torna possível com o aparecimento da escrita, processo por que se criam as condições de abordagem da linguagem como objeto suscetível de manejo e codificação. Assim qualifica Auroux esse vínculo constitutivo entre gramma (letra) e gramatique (gramática): “[...] o florescimento do saber linguístico tem sua fonte no fato de que a escrita, fixando a linguagem, objetiva a alteridade e a coloca diante do sujeito como um problema a resolver." (AUROUX, 1992, p. 23).

É nesse vínculo que se ancoram a função original da gramática como técnica de acesso e compreensão de textos escritos da tradição e a reconfiguração posterior dessa função ou a "mudança de orientação prática da gramática", que passa a consistir em "técnica geral de aprendizagem de uma língua estrangeira", no contexto da revolução tecnológica da gramatização. O traço transversal dessa dupla função encontrase na motivação comum em atribuir sentido à alteridade consistindo esta última seja no corpus textual escrito da tradição literária, na antiguidade clássica, seja em diversidade linguística, 
quando do trabalho de gramatização dos vernáculos, a partir do século XVI. Conforme lembra Auroux, atuando em espaços de oralidade, nossos gramáticos "o que encontram primeiramente é a variação linguística [...]”. A gramatização, geralmente se apoiando sobre uma discussão do que seja o "bom uso", vai reduzir essa variação. (AUROUX, 1992, p. 69).

Essas percepções apontam para pelo menos dois aspectos gerais dos modos com que a reflexão sobre a gramática constitui-se historicamente: por um lado, a relação constitutiva entre gramática e texto (escrito, literário) e, por outro lado, o enfrentamento da variação como campo de (im)possibilidades do próprio gesto de gramatização dos usos linguísticos. Assim, é possível dizer que o desafio do procedimento de reflexão sobre a gramática é, historicamente, aquele de estabelecer a alteridade, de estabilizar aquilo que é constitutivamente heterogêneo: a noção de purismo linguístico permite, em grande medida, objetivar esse desafio no interior sempre de projetos políticos específicos, como o de conferir à língua a função de dispositivo de constituição da ideia de nação (AUROUX, 1992, p. 29). ${ }^{1}$

Com base nessas considerações gerais, proponho levantar elementos de qualificação do estatuto do conhecimento gramatical como componente curricular da disciplina língua portuguesa. Mais especificamente, discutir como o duplo aspecto mencionado, em que se investe historicamente a reflexão sobre a gramática - a relação entre gramática e texto e o problema da variação - , configura-se no percurso histórico de evolução do ensino de língua portuguesa, na escola brasileira, no que respeita particularmente aos currículos e programas de ensino e aos

\footnotetext{
1 Faraco menciona o fato de a "ameaça de sobrepujamento da língua grega pelos falares 'bárbaros' (ou seja, não gregos)" (FARACO, 2017, p. 12) estar entre as motivações socioculturais e políticas em que se baseia o empreendimento de reflexão sobre gramática na antiguidade.
} 
materiais didáticos propostos. Em seguida, proponho contrastar esse estatuto historicamente construído do conhecimento gramatical escolar com práticas de ensino de língua portuguesa atuais, mediadas por estudantes de curso de licenciatura em Letras, por ocasião de realização de estágio em escolas da rede pública da cidade de São Paulo (Brasil).

\section{Gramática escolar e ensino de língua portuguesa}

A seguir, consideremos alguns elementos de qualificação do estatuto do conhecimento gramatical como componentes curriculares do ensino de língua portuguesa, com base em estudos voltados à reconstituição do percurso histórico de formação desse ensino na escola brasileira (ANGELO, 2010; BRITTO, 1997; BUNZEN, 2011; BUNZEN; MEDEIROS, 2016; BUNZEN; NASCIMENTO, 2019; COSTA VAL, 2002; FARACO, 2017; PIETRI, 2010; RAZZINI, 2000; ROJO, 2008; SOARES, 1997; 2002). ${ }^{2}$

\subsection{Gramática escolar, cânon literário e purismo linguístico: o modelo clássico e beletrista}

No processo histórico de gênese e consolidação da disciplina língua portuguesa, na escolabrasileira, oconhecimento gramatical

\footnotetext{
2 Tais estudos representam uma parte da produção acadêmica brasileira voltada à abordagem histórica do ensino da gramática particularmente como componente curricular da disciplina língua portuguesa, na escola brasileira. A restituição do percurso histórico desse componente, com base nas sínteses propostas nesses estudos, tal qual apresentada aqui, consiste em um movimento tanto de cotejo de fatos e fenômenos nelas descritos e qualificados, quanto de proposição de uma operação metodológica de contraste de dois modelos de ensino de língua portuguesa, conforme configurados em duas conjunturas delimitadas sócio-historicamente.
} 
constitui-se em componente curricular que sobredetermina o conjunto de conhecimentos constituídos em objetos de ensino, sendo a codificação da língua nas gramáticas escolares justamente o parâmetro com relação a que se constituem tais objetos, incluídos aqueles atinentes ao conhecimento sobre os usos da palavra em práticas de leitura e produção textual, ou seja, ao eixo retórico do currículo da disciplina, subsidiário em relação ao conhecimento gramatical e nele encontrando suas condições de legitimidade e validade.

Essa função instrumental dos usos da língua (em práticas de leitura e produção textual escrita e oral) com relação aos conteúdos gramaticais concorre para a definição do lugar das coletâneas de textos (seletas, antologias, livros de leitura) nas práticas didáticas: ao compilarem um conjunto de textos, conferindo-lhes unidade e os conformando em um cânon escolar legítimo, essas coletâneas asseguram e recrudescem a concepção de língua codificada nas gramáticas escolares. As condições de possibilidade de existência objetiva — de validade e legitimidade institucional — desse cânon submetem-se, portanto, ao conhecimento gramatical, o que subverte o processo mesmo em que se produz historicamente a reflexão sobre a gramática, apoiado, conforme mencionado, exatamente sobre textos escritos da tradição. Esse papel instrumental ou subsidiário do texto com relação à gramática é um primeiro traço fundante do estatuto do conhecimento gramatical no modelo clássico e beletrista de ensino de língua portuguesa, na conjuntura histórica considerada.

Complementarmente, outro traço fundante refere-se ao princípio de padronização em que se ancora a concepção de língua (língua ou idioma nacional ou língua pátria) da gramática 
escolar. Pode-se dizer que é tal princípio — de correção ou de purismo - que assegura à gramática a função de matriz a partir de que se engendram e se articulam os demais componentes curriculares e objetos de ensino; que lhe assegura, no modelo clássico e beletrista, o estatuto de porto seguro em que se fixa e pelo qual se traduz a própria identidade da disciplina Português. A opção por tal princípio denega, em sentido diametralmente oposto, aquele da variação ou da heterogeneidade linguística.

Ora, tanto a função instrumental do texto com relação à gramática quanto a denegação da variação ou heterogeneidade linguística representam reconfigurações que a forma escolar (LAHIRE, 2008) opera sobre o conhecimento gramatical (e sobre o próprio percurso histórico de reflexão sobre a gramática) ao transformá-lo em objeto de ensino. Esse duplo traço representa a base comum sobre a qual se estabelece historicamente a polêmica em torno do ensino de gramática, ou seja, as disputas e os confrontos - teóricos, epistemológicos e ideológicos - sobre o que e como se ensina quando se pretende ensinar gramática na escola.

Assentam-se sobre essa base comum, no modelo clássico e beletrista, as condições de integração de diferentes perspectivas, concepções linguísticas ou tradições disciplinares que vão informando e conformando historicamente a versão escolar do conhecimento gramatical. Bunzen e Medeiros (2016), por exemplo, ao discutirem o lugar da gramática no currículo humanista do ensino secundário brasileiro, durante a Primeira República, entre os anos 1898 e 1930, assinalam o caráter enciclopédico que adquire tal currículo na transição de diferentes reformas curriculares implementadas no período, o que se dá no cerne da disputa em torno do estatuto e do peso de disciplinas 
clássicas e de disciplinas científicas no ensino de português; segundo os autores, uma disputa pela qual se busca harmonizar "a tradição dos estudos humanistas com a modernidade dos científicos”. (BUNZEN; MEDEIROS, 2016, p. 122).

Assim, como estratégia de autolegitimação, a disciplina Português mantém a tradição greco-latina como discurso fundador do conhecimento gramatical legítimo a ser ensinado e, ao mesmo tempo, desse discurso delimita-se ao aderir ao contemporâneo, traduzido como moderno, ou seja, ao discurso cientificista sobre o qual passam a se embasar diferentes concepções linguísticas e pedagógicas, na virada do século XIX para o século XX. Estratégia ambígua que lhe assegura um duplo valor: a tradição como espaço da estabilidade e o moderno, em seu suposto dinamismo, como índice de evolução. É nessa modulação entre o considerado tradicional e o considerado moderno que se pode qualificar o estatuto do conhecimento gramatical na Gramática expositiva: curso superior, de Eduardo Carlos Pereira: ${ }^{3}$ a tentativa de harmonização do binômio tradicionalmoderno opera, mais especificamente, como combinação de uma perspectiva especular de língua com outra historicista. É esse modelo clássico e beletrista que passa a ser tensionado mais particularmente na virada dos anos 1970 para os anos 1980 e, a partir daí, por mais de três décadas até os dias atuais, quando da elaboração teórica, curricular e didática de um modelo de ensino de língua portuguesa alternativo e concorrente a ele.

Vejamos, a seguir, alguns traços panorâmicos do estatuto do conhecimento gramatical nesse assim designado modelo interacionista.

\footnotetext{
$\overline{3}$ Os autores mencionam a ampla difusão dessa gramática na escola brasileira tendo em vista o conjunto significativo de reimpressões da obra. Assinalam ainda a profusão de gramáticas escolares brasileiras publicadas entre o fim do século XIX e as primeiras décadas do século XX. (BUNZEN; MEDEIROS, 2016, p. 123).
} 


\subsection{Gramática escolar, diversidade textual e polilinguismo: o modelo interacionista}

Para compreender o lugar do conhecimento gramatical no currículo de língua portuguesa na conjuntura intelectual de início de abertura política do Brasil, na virada dos anos 1970 para os anos 1980, é preciso considerar o fenômeno mais amplo, a partir de então, de "retoricização" do currículo, o que consiste em um processo de redefinição curricular pelo qual os usos (retóricos) da palavra em práticas de leitura e produção textual passam a adquirir centralidade na elaboração teórica e aplicada sobre o ensino de língua portuguesa (NONATO, 2019a; 2019b). Tal fenômeno deve ser considerado em estreita imbricação com a circulação de conhecimentos, entre outros, do campo dos estudos linguísticos na instância da formação acadêmica e naquela das políticas públicas de elaboração e implementação curriculares levadas a cabo no período em diferentes pontos do país (GERALDI; SILVA; FIAD, 1996).

O "discurso da mudança"(PIETRI, 2003) que passa a afetar o processo de redefinição curricular do ensino de língua portuguesa consiste em um empreendimento central na história desse ensino por não se tratar apenas de alteração das referências teóricas ou das disciplinas científicas de referência, mas principalmente de alçamento de renovada perspectiva epistemológica sobre a linguagem e seu ensino. Nesse empreendimento, combinam-se pelos menos duas tradições - a epistemologia estruturalista, assentada há mais tempo na academia brasileira, e uma tradição epistemológica que começa a circular e ganhar fôlego explicitamente somente no último quartel dos anos 1970 e que poderia ser genericamente designada como perspectiva textual, 
pragmática ou discursiva de linguagem e de ensino de língua. Trata-se de um amálgama não desprezível porque permite pensar sobre a língua tanto em seus planos fonético-fonológico e morfossintático e em seus níveis lexical e frasal —, quanto em seus planos semântico e pragmático e em seu nível textual, tendo em vista o conjunto de práticas comunicativas em que se inserem os falantes.

Em que consiste mais precisamente a emergência dessa dupla tradição epistemológica e quais seus efeitos na busca por um currículo renovado para o ensino de língua portuguesa e, mais especificamente, de gramática? Em primeiro lugar, cabe considerar que se trata de inverter o sinal no que respeita ao lugar da gramática no currículo: de componente que pilota o conjunto de objetos de ensino, conforme mencionado, ela passa a componente subsidiário às práticas de leitura e produção escrita. É o que está marcado na ambiguidade do título do conhecido livro de Sírio Possenti - Por que (não) ensinar gramática na escola? (POSSENTI, 1996). Em segundo lugar, trata-se de revisitar os dois aspectos fundantes da reflexão multicentenária sobre a gramática, conforme mencionado: a relação entre gramática e texto e o estatuto da variação ou heterogeneidade linguística.

No que respeita à relação entre gramática e texto, aportes gerados em diferentes tradições disciplinares na academia brasileira (estudos textuais, estudos discursivos, enunciativos — incluídos os estudos bakhtinianos — , estudos funcionalistas, além de estudos na área de linguística aplicada (ANTUNES, 2007; FARACO, 2017; NEVES, 1990; TRAVAGLIA, 2001; 2003; 2010), tanto fornecem uma lupa para a compreensão de recursos linguísticos que afetam a unidade textual — caso 
dos operadores argumentativos e conectores ou das expressões definidas que promovem a progressão textual $(\mathrm{KOCH}, 2004)$ quanto permitem redimensionar a função de recursos dos planos fonético-fonológico e morfossintático, bem como daqueles relativos aos níveis lexical e frasal da língua, no processo de produção de efeitos de sentido na unidade textual. É assim que o desenvolvimento de uma teorização e de uma descrição robustas de fenômenos, processos e recursos, nas ações de produção e recepção de textos, bem como o interesse pelo processo de produção do conhecimento constitutivo da própria prática de produção da linguagem (MARCUSCHI, 2007) fornecem categorias e dispositivos analíticos suscetíveis de auxiliar a compreensão da diversidade de gêneros textuais-discursivos que circulam em práticas comunicativas de diversa natureza, bem como de recursos que, altamente sensíveis a tais gêneros, constroem a materialidade semiótica de textos escritos, orais e multimodais.

Com relação ao estatuto da variação ou heterogeneidade linguística, um conjunto amplo de aportes gerados nas áreas dos estudos sociolinguísticos, dos estudos funcionalistas, dos estudos em antropologia linguística e dos estudos aplicados brasileiros, entre outros, permite tanto descrever fenômenos de variação e mudança linguística do português brasileiro, quanto qualificar uma gama diversa de recursos, códigos, posturas, processos de estilização, de oficialização e de (des)regulamentação de usos linguísticos em práticas comunicativas não menos diversas, incluídos os contextos constitutivamente polilinguísticos (BAGNO, 2002; BENTES, 2010; BENTES; MARIANO, 2013; BORTONI-RICARDO, 2005; CASTILHO, 1987; SIGNORINI, 2002). A variação ou heterogeneidade linguística ou o 
polilinguismo, nessa direção, sendo considerados não um traço acessório da língua em uso, mas "estado da língua e recurso do falante", conforme a bastante apropriada formulação proposta por Signorini (2002, p. 122). Para a autora, é exatamente o postulado da variação como propriedade constitutiva da língua que fica nas margens das evidências recobertas pela noção de língua nacional, a qual se encontra justamente na base do modelo clássico e beletrista.

Ora, o acordo comum em que se ancoram os aportes teóricos mencionados encontra-se no postulado de que a produção linguística - mais especificamente, a constituição dos recursos gramaticais da língua - é função da agência distribuída de interagentes em práticas comunicativas situadas institucional e sócio-culturalmente, não preexistindo absolutamente a elas. É sob tal ótica que se pode considerar a conhecida sugestão didática formulada por Geraldi (1991) de reposicionar a gramática como prática de análise linguística no currículo de língua portuguesa, em interface e em estreito vínculo com dois outros componentes curriculares: as práticas de leitura e de produção textual. Incorporada a diversas propostas curriculares desde a década de 1980, no Brasil, essa sugestão é recuperada nos Parâmetros Curriculares Nacionais de Língua Portuguesa para o Ensino Fundamental (BRASIL, 1998), nas Orientações Curriculares para o Ensino Médio (BRASIL, 2006) e, mais recentemente, recategorizada como "análise linguística e semiótica", na Base Nacional Comum Curricular. (BRASIL, 2017). "Análise linguística" ou "reflexão sobre a língua" ou, ainda, "análise linguística e semiótica" (BEZERRA; REINALDO, 2013; MENDONÇA, 2006; LOURENÇO; ARAÚJO, 2019; TRAVAGLIA, 2010) são, em seu conjunto, expressões que 
figuram o interesse em conferir ao conhecimento gramatical o estatuto de conhecimento de natureza fundamentalmente pragmática, no currículo de língua portuguesa. Trata-se, assim, de expressões que se opõem simbolicamente à histórica vocação taxonômica em que esteve hegemonicamente ancorado o ensino do conhecimento gramatical nesse currículo.

Pode-se dizer, portanto, que é em um cenário de disputa histórica que o estatuto do conhecimento gramatical reconstituise no currículo de língua portuguesa, nas relações de aproximação e de distanciamento e, mais comumente, de mixagem, entre o modelo clássico-beletrista e o modelo interacionista de ensino, conforme caracterizados. É, por fim, na tensão entre tais modelos de ensino que se pode compreender um conjunto amplo de desafios com que se confrontam as professoras e os professores quando do ensino de gramática na aula de língua portuguesa, atualmente. A seguir, vejamos como parte desses desafios ganha corpo em práticas didáticas mediadas por um estudante universitário, licenciando em processo de formação acadêmica ${ }^{4}$.

\section{Gramática e formação do professor de língua portuguesa}

Nesta seção, pelo recurso a um relatório de estágio elaborado como produto final do Curso de Metodologia de Ensino do Português por estudante do Curso de Licenciatura em Letras da Faculdade de Educação da Universidade de São Paulo, proponho discutir o conjunto de considerações expostas. Com base no registro escrito de práticas de ensino conforme

\footnotetext{
4 Embora considerando, conforme discutido, o duplo aspecto em que se configura a incorporação da gramática na prática escolar — a relação entre gramática e texto e o problema da variação linguística —, em função de limite de espaço, opto por considerar, na descrição e análise dos dados, a seguir, apenas o primeiro aspecto, deixando para outro momento a abordagem do problema central da variação.
} 
representadas no relatório, procuro interpretar o processo de implementação, por ocasião de realização de estágio de regência, de um projeto didático focado sobre o funcionamento do verbo no texto poético 5 .

No quadro, a seguir, aparecem condensados dados de identificação do relatório ${ }^{6}$, além daqueles relativos aos objetos ensinados e aos dispositivos didáticos empregados na implementação do projeto de ensino.

\section{Quadro 1 - Dados do relatório selecionado - Gramática}

$5 \quad$ As práticas de ensino de língua portuguesa de que toma parte o licenciando na posição de estagiário são alçadas por ele ao estatuto de objeto de reflexão por meio do relatório de estágio. Nele, saberes e métodos de ensino são colocados a distância e se tornam objetos de discurso - objetos de descrição e de análise. Como têm mostrado diversos estudos sobre a formação do professor de língua portuguesa (GOMES-SANTOS; SEIXAS, 2012; SILVA, 2013; SILVA; MELO, 2008), a consideração desse artefato material da prática de formação profissional pode trazer múltiplos indícios de questões, problemas e desafios que o processo de atualização dos saberes e métodos de ensino da disciplina língua portuguesa coloca para o professor em formação. Do ponto de vista de sua abordagem como dado da pesquisa sobre formação docente, não é inútil lembrar que o exercício de interpretação dos rastros das práticas de ensino nele representadas constitui-se em uma interpretação sobre outra interpretação, uma espécie de metainterpretação. Trata-se, nessa direção, de uma abordagem orientada pelo interesse em qualificar tais rastros como indícios dos processos históricos de disciplinarização do ensino de língua portuguesa de que essas mesmas práticas tomam parte.

6 Os dados considerados neste estudo integram o corpus do projeto de pesquisa Formação inicial e letramento do professor de língua portuguesa: conceber, implementar e avaliar projetos de ensino (GOMES-SANTOS, 2019). A seleção do relatório em tela, neste estudo, considerou: i) o componente curricular nele focalizado (gramática), tendo em vista a discussão proposta neste estudo, e ii) a supervisão explícita a que procedi, na condição de professor formador, de seu processo de produção. Cabe assinalar que a consideração de um único relatório é motivada pelo interesse em abordar, como unidade global de análise, especificamente a seção do relatório em que o processo de implementação do projeto de ensino aparece descrito e analisado: o fato de se tratar de seção textual extensa dificulta a consideração de dois ou mais relatórios. Embora não se possa proceder a generalizações com base no relatório eleito, é possível tomá-lo em seu caráter indiciário (ilustrativo) com relação a ênfases temáticas, estilos de descrição, ensaios analíticos, etc., ensejados em um conjunto de outros relatórios que compõem o banco de dados de que ele faz parte. 


\begin{tabular}{|c|c|c|}
\hline \multicolumn{2}{|c|}{ Descritor/Título } & $\begin{array}{l}\text { A flor brotou no asfalto do K.? Experiência } \\
\text { e vivência de estágio de língua portuguesa } \\
\text { em uma escola estadual paulista }\end{array}$ \\
\hline \multicolumn{2}{|c|}{ Sumário do relatório } & $\begin{array}{l}\text { Resumo } \\
\text { Palavras-chave } \\
\text { Parte I: O do-entorno do ensino } \\
\text { Parte II: Quando o professor se faz poeta } \\
\text { Parte III: A flor consegue romper o asfalto } \\
\text { Bibliografia } \\
\text { Anexos } \\
\text { [30 páginas] }\end{array}$ \\
\hline \multicolumn{2}{|c|}{$\begin{array}{l}\text { Escola } \\
\text { Ano e Nível de Ensino } \\
\text { Faixa etária dos alunos } \\
\text { Período - Duração }\end{array}$} & $\begin{array}{l}\text { - Escola Estadual, localizada em São Paulo } \\
\text { (SP, Brasil), bairro da Luz, região central } \\
\text { - } 8^{\circ} \text {. Ano Ensino Fundamental } \\
\text { - Entre } 12 \text { e } 14 \text { anos de idade } \\
\text { - } 2^{\circ} \text {. Semestre de } 2018-08 \text { (oito) aulas }\end{array}$ \\
\hline \multicolumn{2}{|c|}{ Objetos ensinados } & $\begin{array}{l}\text { - Funcionamento dos verbos em poemas: } \\
\text { - Modos do verbo: infinitivo, indicativo, } \\
\text { subjuntivo e imperativo } \\
\text { - Tempos verbais } \\
\text { - Texto poético: temática amorosa- } \\
\text { perspectiva feminina; definição de poesia; } \\
\text { forma soneto; métrica, rima e verso }\end{array}$ \\
\hline \multirow{2}{*}{$\begin{array}{l}\text { Dispositivos } \\
\text { didáticos }\end{array}$} & $\begin{array}{l}\text { Coletânea de } \\
\text { textos }\end{array}$ & $\begin{array}{l}\text { > Soneto "Amor é fogo que arde sem se ver", } \\
\text { de Camões " } \\
>\text { Poema "Ainda que mal", de Carlos } \\
\text { Drummond de Andrade } \\
\text { > Poema "Bilhete", de Mario Quintana } \\
\text { > Poema "IX", de Hilda Hilst } \\
\text { > Poema "Casamento", de Adélia Prado }\end{array}$ \\
\hline & $\begin{array}{l}\text { Instrumentos } \\
\text { didáticos e } \\
\text { formas de } \\
\text { trabalho escolar }\end{array}$ & $\begin{array}{l}\text { - Leitura oral de poemas seguida de } \\
\text { comentários orais com anotações na lousa } \\
\text { - Exposição oral em diálogo com a turma (Par } \\
\text { Pergunta-Resposta) acompanhada de síntese } \\
\text { de conteúdos na lousa } \\
\text { - Tarefa de produção escrita } \\
\text { - Tarefa de análise linguística }\end{array}$ \\
\hline
\end{tabular}

Fonte: Quadro sinóptico elaborado pelo autor.

A seguir, observemos como os dois componentes 
estruturantes do projeto de ensino (objetos ensinados e dispositivos didáticos $)^{7}$ ganham corpo nas práticas didáticas representadas no relatório, bem como quais os desafios que a abordagem da gramática coloca para o professor em formação.

\subsection{Gramática e texto em uma turma de $8^{\circ}$. ano do ensino fundamental: o funcionamento dos verbos no texto poético}

A relação entre Perseu e a Górgona é complexa: não termina com a decapitação do monstro. Do sangue da Medusa nasce um cavalo alado, Pégaso; o peso da pedra pode reverter em seu contrário; de uma patada, Pégaso faz jorrar no monte Hélicon a fonte em que as Musas irão beber [...]. (CALVINO, 1990, p. 17).

O relatório intitulado A flor brotou no asfalto do K.? Experiência e vivência de estágio de língua portuguesa em uma escola estadual paulista expõe o processo de implementação de um projeto didático em torno do funcionamento de verbos no texto poético, junto a alunos do $8^{\circ}$ Ano do Ensino Fundamental adolescentes na faixa etária entre 12 e 14 anos de idade, "público proveniente de famílias pobres, vulneráveis, com presença ampla de imigrantes. Muitas das famílias são sustentadas com trabalho informal" [LPF, Gramática, 2018, p. 10] ${ }^{8}$ — de uma escola da rede estadual de ensino de São Paulo (SP, Brasil) localizada no bairro da Luz, região central da capital, em um percurso de oito aulas, no segundo semestre de 2018.

Esse objeto é delimitado pela seleção de tópicos de conteúdo

\footnotetext{
7 Para a caracterização global do percurso de implementação dos projetos de ensino, recorro, na descrição e análise do relatório, à contribuição dos estudos sobre o trabalho docente em uma perspectiva didática desenvolvidos por Bernard Schneuwly, Joaquin Dolz e seus colaboradores. (SCHNEUWLY; DOLZ, 2009).

8 A inserção entre colchetes remete à codificação do relatório de estágio considerado no corpus do projeto de pesquisa mencionado. (GOMES-SANTOS, 2019).
} 
particulares, de natureza tanto propriamente gramatical (tempos e, principalmente, modos verbais), quanto textual/composicional (forma soneto, métrica, rima, verso), passando por aqueles de natureza temática (os temas "amor" e "feminino", presentes nos poemas). A coletânea de textos escritos em que se baseia a abordagem desses tópicos de conteúdo comporta cinco poemas.

$\mathrm{O}$ projeto estrutura-se em quatro fases ou atividades escolares, cada uma das quais comportando duas aulas. O dispositivo didático global acionado ao longo desse percurso combina centralmente o uso da leitura oral, acompanhada de identificação do vocabulário, com o comentário ou a explicação de textos. Esta última, um instrumento sedimentado na cultura escolar e no ensino de língua portuguesa (CARRETER; LARA, 1962), antecede e introduz a abordagem dos tópicos de conteúdo gramaticais eleitos, com auxílio da lousa. O recurso à lousa como suporte de registro e "institucionalização de conhecimentos" (SCHNEUWLY; DOLZ, 2009) sobre o texto adquire um caráter singular na ação didática. Nos termos do licenciando,

[...] após a primeira leitura, retornamos ao poema para identificar todos os verbos presentes, os quais circulamos. Enquanto íamos avançando, buscava demonstrar as etapas do processo de leitura na lousa, materializar por exemplo em cores diferentes de giz os verbos no infinito e no indicativo; os alunos foram orientados no começo da aula a reproduzirem a lousa no caderno, fornecendo também um caminho para o prosseguimento dos estudos e de leituras futuras. Logo de início, dividira a lousa em quatro colunas, que nomeei junto com os alunos: à esquerda, 'o que já sabemos'; o poema, onde íamos anotando os passos da leitura; uma área de 'rascunho', com observações e contribuições não definitivas dos alunos; e à direita, 'conceitos' (poesia, soneto e modo indicativo). A lousa tentava mimetizar o caminho da aula. [LPF, Gramática, 2018, p. 13]. 
$\mathrm{O}$ uso desse conjunto de instrumentos - leitura oral e explicação do texto seguidas de sistematização de conhecimentos de natureza temática e gramatical - remete ao objetivo didático de recepção do texto (de seu tema, de seu vocabulário e de seus recursos expressivos) e prepara o terreno para a tarefa de produção escrita, no fim da aula dupla, a saber: “[...] algumas linhas (de 3 a 5 linhas, em torno de 1 parágrafo) sobre o amor, dialogando com o poema e com sua definição." [LPF, Gramática, 2018, p. 13]. Além da função de ensino dos tempos e do modo indicativo do verbo, a formulação dessa tarefa de produção tem ainda a função de regulação - checagem dos efeitos do uso dos instrumentos sobre os modos de aprendizagem dos alunos materializados nos textos por eles produzidos.

A percepção de certo "desnivelamento grande entre os alunos" no que respeita a conhecimentos prévios sobre nomenclatura gramatical, nessa primeira atividade do percurso, impulsiona o licenciando a operar uma inversão, com relação à atividade anterior, dos componentes previstos para a segunda atividade escolar (na segunda aula dupla). Nessa ocasião, opta por iniciar a atividade pela sistematização de conceitos, ou seja, pelo recurso à metalinguagem precedendo a leitura do texto. $\mathrm{O}$ efeito dessa inversão é assinalado pelo licenciando nos seguintes termos:

Tendo já copiado o poema "Ainda que mal" no centro da lousa - o que por si motivou perguntas e afirmações dos alunos: "isso não é soneto, prô" — iniciei a aula retomando conceitos gramaticais. $\mathrm{E}$ repliquei $\mathrm{o}$ modelo de perguntas e respostas, sem sucesso. As respostas foram escasseando, os alunos dispersaram sua atenção e, quando chegamos ao poema (sem que a explicação gramatical tenha se consolidado), a leitura pautou-se menos pelos sentidos do poema e mais pela demonstração da variabilidade da forma verbal. Isso 
comprometeu não só a relação com o texto como o passo seguinte, a exposição e conceituação do modo subjuntivo. [LPF, Gramática, 2018, p. 14].

O esmaecimento da recepção textual em favor da sistematização ("retomada") prévia de conhecimentos de natureza gramatical (conjugação verbal, por exemplo) impacta não apenas a leitura oral posterior do terceiro poema da coletânea ("Bilhete") — aparentemente sem maior engajamento por parte dos alunos —, como também a tarefa proposta em torno dele: “[...] pedi que os alunos transpusessem o poema para o modo subjuntivo, ocasionando alterações não somente na oração subordinada como nos verbos das orações principais. Resultado: apenas uma aluna entregou (Anexo 2).” [LPF, Gramática, 2018, p. 14].

A opção feita na atividade escolar em questão é redimensionada na atividade posterior, terceira do percurso didático trilhado. Nela, o licenciando opta por retomar a precedência da experiência de leitura do texto sobre a abordagem e sistematização de tópicos gramaticais de conteúdo, restituindo a ponte almejada entre literatura e gramática. Em seus termos: "[...] ao invés de passar na lousa, imprimi os poemas de Hilda Hilst e Adélia Prado e os distribuí para os alunos, sentados num círculo no meio da sala — eu e V. ${ }^{9}$ compúnhamos o mesmo círculo." [LPF, Gramática, 2018, p. 16].

O compartilhamento de comentários sobre os poemas, na sequência da leitura oral, incide sobre os temas - amor e feminismo - representados no poema. Entre as três atividades propostas, esta é aquela que mais se aproxima da representação que o licenciando faz de um estilo interacionista de mediação

9 Professora titular da turma em que ocorre o estágio. 
didática - "Foi a aula mais interacionista de todas e funcionou muito bem.”[LPF, Gramática, 2018, p. 16]. É também a atividade que parece mais explicitamente indiciar o impacto da natureza do objeto de conhecimento (nesse caso, o tópico temático do texto), associado à forma de trabalho escolar eleita (o círculo ou a roda de conversa), no engajamento dos alunos quando do comentário sobre o texto. Nas palavras do licenciando:

De pronto já surgiu a questão do feminismo e do machismo - ao responder o que é feminismo, um aluno disse que "feminismo é o contrário de machismo", gerando a tréplica de uma aluna sobre a diferença entre ambos. V. também interagiu bastante, acredito porque algumas questões afetam diretamente a ela e sua trajetória pessoal - foi o momento em que a vi sair do lugar esperado de professor, falando com propriedade (e os alunos escutando-a), provocando. Curioso que sobre um tema muito presente durante a eleição - o papel da mulher na sociedade brasileira - e sobre o qual paira um tabu (com o avanço do Escola sem Partido e de explicações simplistas, mas recorrentes), conseguimos avançar, causar um debate entre os alunos. [LPF, Gramática, 2018, p. 16].

O design dessa atividade - precedência da leitura oral e do comentário dos poemas com relação à abordagem de tópicos de conteúdo gramaticais —, tem como ponto de chegada a formulação de outra tarefa de produção escrita: “[...] na atividade no final da aula, pedimos que eles se posicionassem do ponto de vista do interlocutor da eu-lírica, respondendo à pergunta expressa no poema: por que quer não só o corpo, mas também a alma, da mulher?" [LPF, Gramática, 2018, p. 17].

Por fim, a atividade que encerra o percurso didático consiste em "uma atividade mais livre, menos orientada de leitura". [LPF, Gramática, 2018, p. 18]. Trata-se de uma atividade em grupo, em 
torno de um livro de poemas, na qual a "instância do exercício" (BATISTA, 1997) ou a tarefa proposta ocupa o primeiro plano da interação didática. Assim são descritos pelo licenciando o objetivo e a execução da tarefa:

Distribuí a sala em seis grupos (mesclando os agrupamentos voluntários dos alunos), cada um com um livro de poemas, os mesmos de onde selecionei os poemas. O objetivo era que eles tivessem contato não com poemas isoladamente, mas com o objeto-livro, que manejassem os livros, escolhendo um poema que deveria ser copiado e dedicado a outro aluno da sala. Eles deveriam, então, escrever uma dedicatória, demonstrando algo do poema (algum rastro linguístico) que relacionasse o presenteado e o dedicador. [...] Enquanto eles escolhiam os poemas, eu e V. íamos passando de grupo em grupo, motivando-os que trabalhassem juntos, ajudando alguns mais tímidos, lendo alguns poemas junto. [LPF, Gramática, 2018, p. $18]$.

Notemos que, no conjunto das atividades implementadas (especificamente, na primeira, na terceira e nessa final, a quarta), parece esboçar-se certa suspeita sobre a efetiva possibilidade de ensino de tópicos gramaticais com base na leitura do texto: na relação entre gramática e texto, o licenciando acaba por constatar a não obviedade da própria possibilidade de estabelecimento de ponte entre os dois componentes, conforme objetivo didático previsto ainda no planejamento do projeto de ensino.

No enfrentamento do desafio de construção da ponte entre gramática e texto (literário), o projeto didático implementado demarca explicitamente um objeto de natureza gramatical (verbo: tempos, modos, conjugação) como recurso de incremento de outro objeto - o poema, mais especificamente os tópicos temáticos nele representados (o amor; a perspectiva feminina 
sobre a relação amorosa). É a experiência de leitura que parece estar o tempo todo na expectativa, na representação e na atuação do licenciando, no decorrer do percurso didático trilhado.

A suposição de um modelo interacionista de ensino de língua portuguesa como referência na concepção do projeto didático é o que gera, no percurso de sua implementação efetiva, um estilo de mediação didática, poderíamos dizer, por tateios, mediação dinâmica, suscetível de ser "quebrada" ("resolvi quebrar a metodologia proposta") e de se refazer ao longo do percurso como metodologia aberta. E por quê? Porque, dado o perfil dos alunos e da comunidade escolar e circunvizinha à escola, dadas as condições infraestruturais da escola e dada a precariedade das condições de trabalho das professoras e dos professores, não seria possível pensar em ensinar conhecimento gramatical prescindindo da experiência de leitura do texto e de repertórios textuais (como os poemas selecionados) a que os alunos não teriam acesso caso não estivessem na escola - locus de produção, a um só tempo e paradoxalmente, de promoção de acesso e de distinção de modos de acesso ao capital cultural.

Nesse cenário, é uma motivação de empoderamento do aluno como leitor crítico que parece mover as ações e opções didáticas do licenciando ao longo da implementação do projeto didático. A tentativa de estabelecimento de vínculo entre gramática e texto adquire espessura no calor das tensões objetivas das práticas didáticas, gerando um posicionamento sobre tal vínculo e, principalmente, catalisando a atividade reflexiva do licenciando sobre as condições materiais de produção das relações sociais no espaço escolar; ${ }^{10}$ atividade reflexiva materializada na metáfora formulada sob forma de interrogação no título do relatório (A

10 Consideremos que estamos em uma escola localizada na região central de uma das maiores metrópoles do mundo, a cidade de São Paulo. 
flor brotou no asfalto do K.?) e no subtítulo da seção III ("A flor consegue romper o asfalto?"). Nos termos do licenciando,

Será possível gramaticalizar a literatura sem reduzi-la? $\mathrm{Ou}$, pela outra face da mesma questão, literaturizar a gramática? Acredito que sim, como tentei demonstrar no relato da regência. Somente assim conseguiremos avançar na reflexão acerca da língua portuguesa pelos alunos, o que traz consequências também para o professor e a escola, que recebem novos usos, novas problemáticas. Para tal, entretanto, a escola deve estar preparada, estruturada; ela deve perceber, na atual conjuntura política, suas próprias rachaduras, de onde podem brotar flores. Em meio à dureza, a arte e a literatura (integradas por uma concepção única da língua) indicam caminhos possíveis e, talvez, únicos. [LPF, Gramática, 2018, p. 20].

No jogo complexo entre gramática e texto, este último é o que daria a "leveza" (como um cavalo alado, um Pégaso nascido do sangue maldito da Medusa, conforme a metáfora de Calvino) aos processos de apropriação do capital cultural pelo aluno (incluído o conhecimento gramatical): o texto, sua recepção e produção, como flor que brota do chão de práticas de ensino de gramática descontextualizadas, fragmentadas e desprovidas de sentido. Nessa direção, recurso didático e técnica de aprendizagem de uma língua talvez ainda longínqua - a língua da escola. Mas também locus de reconfiguração possível do lugar histórico para o qual essa mesma língua foi destinada na escola.

\section{Considerações finais}


Neste estudo, propus descrever e analisar o estatuto da gramática como componente curricular da disciplina língua portuguesa, considerando tanto os modos como ela se configura na tradição escolar brasileira, quanto em práticas de ensino de língua portuguesa atuais mediadas por um estudante de licenciatura em Letras, por ocasião de realização de estágio em escolas da rede pública da cidade de São Paulo (Brasil).

Mais especificamente, a operação metodológica ensejada consistiu, por um lado, em restituição panorâmica do estatuto curricular do conhecimento gramatical pela qualificação geral de dois modelos de ensino de língua portuguesa (modelo clássico e modelo interacionista) e, por outro lado, em identificação e problematização de elementos didáticos desses modelos no processo de implementação do projeto de ensino sobre o funcionamento do verbo no texto poético. A hipótese é de que, nas práticas didáticas de que tomam parte os futuros professores de língua portuguesa, atualiza-se um conjunto de desafios sedimentados na tradição escolar, além daqueles que emergem de maneira inelutável em decorrência das condições materiais em que se constituem as práticas comunicativas e as ações verbais de professores e alunos em sala de aula.

Tais problemas e desafios, como procurei mostrar quando da análise apresentada, recuperam a relação constitutiva entre gramática e texto (escrito, literário). Esse aspecto adquire nuanças particulares em cada um dos modelos de ensino de língua portuguesa. No modelo clássico, a ênfase incide sobre a função instrumental ou auxiliar do texto com relação à gramática; no modelo interacionista, por sua vez e inversamente, a ênfase incide sobre a função da gramática como recurso subsidiário à recepção e produção do texto e, por essa via, à incorporação ativa 
de múltiplos repertórios culturais em práticas comunicativas diversas. As práticas de ensino em que se inserem os licenciandos por ocasião de implementação de projetos didáticos no âmbito do estágio de regência, longe de espelharem um ou outro desses modelos, ilustram tensões decorrentes de processos de mixagem ou entrecruzamento de elementos de ambos, embora com explícita identificação - no caso de que tratei — com os pressupostos teóricos, epistemológicos e ideológicos do modelo interacionista.

No projeto de ensino do funcionamento dos verbos no texto poético, o desafio é aquele de construção de uma ponte entre gramática e texto (literário). No enfrentamento desse desafio, a crença é de que a abordagem da gramática não pode prescindir da leitura do texto, da detecção de seus tópicos temáticos, da identificação de seus elementos composicionais e da definição de seu léxico. Nessa configuração, a abordagem do tópico gramatical é um apêndice no trabalho de ensino. Se há tentativa de construção da ponte visada entre gramática e texto, o gesto didático pende para este último, para o conhecimento de natureza textual (temas e seu sentido na arquitetura textual).

Talvez se possa dizer que tal opção didática representa, de certa maneira, uma atualização dos próprios modos como se estabelece historicamente a relação entre gramática e texto na tradição de reflexão sobre a linguagem, ainda entre os gregos, em que a gramática se configura como técnica de leitura do texto. No projeto didático implementado, a leitura do texto é dispositivo de identificação e atribuição de sentido ao tópico gramatical eleito como objeto de ensino. Para usar, às avessas, uma formulação conhecida no campo da pesquisa acadêmica brasileira sobre ensino de língua portuguesa, poder-se-ia dizer 
que, no caso em tela, a gramática é pretexto para o ensino do texto. Do ponto de vista didático, tratar-se-ia de "inversão dos procedimentos didático-metodológicos assumidos, pela adoção de um caminho que proporcione aos alunos oportunidades de observar, refletir, analisar e descobrir" (COSTA VAL, 2002, p. 121); de inversão do "caminho tradicional — teoria-exemploexercício". (COSTA VAL, 2002, p. 119).

O que estaria na base desse redimensionamento da relação entre gramática e texto? Talvez o suposto de que o nível textual e o plano pragmático da língua, ou seja, a dimensão dos usos linguísticos em práticas de letramento (leitura e produção textual) permite gerar maior engajamento dos alunos na aula de língua portuguesa; permite ainda incrementar seus modos de apropriação do texto, de produção de sentido e, nessa direção, pode promover a atitude crítica do sujeito, seu empoderamento em práticas comunicativas diversas em que é suscetível de se inserir. Trata-se, assim, de uma finalidade que busca delimitarse da tradição hegemônica de abordagem do conhecimento gramatical na aula de língua portuguesa, tal como preconizada no modelo clássico e beletrista, sobretudo nos valores de pureza do idioma e de caráter elevado do cânon literário.

Porfim, pode-se dizer que, no projeto didático implementado, o que está fundamentalmente em jogo, por um lado, é o desafio de tomar o conhecimento gramatical como problema de produção da significação. Nessa direção, a questão formulada por Franchi mantém-se atual: “A questão mais importante para a teoria gramatical é a seguinte: por que e como as expressões das línguas naturais significam aquilo que significam? No centro da gramática se coloca, mesmo quando se faz sintaxe, o problema da significação." (FRANCHI, 1987, p. 14). 
Por outro lado, o que também entra em jogo é o desafio de considerar o conhecimento gramatical como problema de produção do sujeito ou de subjetivação do sujeito na forma escolar, sobretudo do sujeito-aluno. Não parece casual que grande parte dos relatórios de estágio mencionem esse problema quando da descrição das práticas escolares, que assinalem o silenciamento da voz do aluno no cotidiano e na vida da escola. Nesse caso, toca-se fundamentalmente no problema de "o que" a escola faz com a língua do aluno e com que aluno falante ela sonha. A esse propósito, também a sugestão de Franchi (1987) aponta um caminho: a criatividade como categoria heurística para compreender os usos linguísticos, mas também, poderíamos acrescentar, como postura política suscetível de dar visibilidade e potencializar a efervescência de práticas comunicativas escolares e não escolares que buscam resistir em diferentes pontos do país.

\section{Referências}

ANGELO, Graziela. A gramática e o ensino de língua portuguesa: à busca de compreensão. Revista Brasileira de Linguística Aplicada, Belo Horizonte, v. 10, n. 4, p. 931-947, 2010.

ANTUNES, Irandé. Muito além da gramática: por um ensino de línguas sem pedras no caminho. São Paulo: Parábola Editorial, 2007.

AUROUX, Sylvain. A revolução tecnológica da gramatização. Campinas, SP: Editora da Unicamp, 1992.

BAGNO, Marcos. (org.). Linguística da norma. São Paulo: Edições Loyola, 2002.

BATISTA, Antônio Augusto Gomes. Aula de português discurso e saberes escolares. São Paulo: Martins Fontes, 1997. 
BENTES, Anna Christina. Linguagem oral no espaço escolar: rediscutindo o lugar das práticas e dos gêneros orais na escola. In: ROJO, Roxane; RANGEL, Egon. (org.). Explorando o ensino: Língua Portuguesa. Brasília: Ministério da Educação, 2010. p. 15-35.

BENTES, Anna Christina; MARIANO, Rafaela D. A linguagem dos manos: é possível falar sobre um registro popular paulista? In: CUNHA, Maria Angélica F. da; CEZARIO, Maria Maura (org.). Linguística centrada no uso: uma homenagem a Mário Martelotta. Rio de Janeiro: Mauad, 2013. p. 147-161.

BEZERRA, M. A.; REINALDO, M. A. Análise linguística, afinal, a que se refere? São Paulo: Cortez, 2013.

BORTONI-RICARDO, Stela Maris. Nós cheguemu na escola, e agora? Sociolinguística e Educação. São Paulo: Parábola Editorial, 2005.

BRASIL. Base Nacional Comum Curricular. Brasília: Ministério da Educação, Secretaria de Educação Básica, 2017.

BRASIL. Orientações curriculares para o Ensino Médio. Linguagens, códigos e suas tecnologias. Brasília: Ministério da Educação, Secretaria de Educação Básica, 2006.

BRASIL. Parâmetros Curriculares Nacionais. Terceiro e Quarto Ciclos do Ensino Fundamental: Língua Portuguesa. Brasília: Ministério da Educação, Secretaria de Ensino Fundamental, 1998.

BRITTO, Luiz Percival Leme. A sombra do caos: ensino de língua $\mathrm{x}$ tradição gramatical. Campinas: Mercado de Letras / Associação de Leitura do Brasil, 1997.

BUNZEN, Clécio. A fabricação da disciplina escolar Português. Revista Diálogo Educacional, Curitiba, v. 11, p. 885-911, 2011. BUNZEN, Clécio; MEDEIROS, Rejane Rodrigues Almeida de. O ensino de gramática na primeira república (1889-1930): uma análise da Gramática Expositiva, de Eduardo Carlos Pereira. 
Linha D’ Água (Online), São Paulo, v. 29, n. 1, p. 119-141, 2016.

BUNZEN, Clécio dos Santos; NASCIMENTO, Gláucia Renata Pereira do. Gramática na sala de aula: algumas reflexões sobre o ensino dos substantivos. Letras, Santa Maria, v. 29, n. 58, p. 249-275, 2019.

CALVINO, Ítalo. Leveza. In: CALVINO, Ítalo. Seis propostas para o próximo milênio. São Paulo: Companhia das Letras, 1990. p. 12-41.

CARRETER, Fernando Lázaro; LARA, Cecília de. Manual de explicação de textos - Cursos Médio e Superior. São Paulo: Editora Centro Universitário, 1962.

CASTILHO, Ataliba Teixeira de. Variação linguística, norma culta e ensino da língua materna. In: SUBSÍDIOS à proposta curricular de língua portuguesa para o $1^{\circ}$ e $2^{\circ}$ graus. Coletânea de textos. São Paulo: Secretaria de Educação/CENP (Coordenadoria de Estudos e Normas Pedagógicas), 1987. v. 1, p. 53-59.

COSTA VAL, Maria das Graças. A gramática do texto, no texto. Revista Estudos Linguísticos, Belo Horizonte, v. 10, n. 2, p. 107-133, 2002.

FARACO, Carlos Alberto. Gramática e ensino. Diadorim, Rio de Janeiro, v. 19, n. 2, p. 11-26, 2017.

FRANCHI, Carlos. Gramática e criatividade. Trabalhos em Linguística Aplicada (UNICAMP), [s. l.], n. 9, p. 5-45, 1987.

GERALDI, João Wanderley. Portos de passagem. São Paulo: Martins Fontes, 1991.

GERALDI, João Wanderley; SILVA, Lilian Lopes Martin da; FIAD, Raquel Salek. Linguística, ensino de língua materna e formação de professores. DELTA, [s. l.], v. 12, n. 2, p. 307-326, 1996.

GOMES-SANTOS, Sandoval Nonato. Formação inicial e 
letramento do professor de língua portuguesa: conceber, implementar e avaliar projetos de ensino (Projeto de Pesquisa). Conselho Nacional de Desenvolvimento Científico e Tecnológico (CNPq), Bolsa de Produtividade em Pesquisa 310898/2015-3, 2019.

GOMES-SANTOS, Sandoval Nonato; SEIXAS, Caroline. Gêneros textuais da formação docente inicial: o projeto de ensino de língua portuguesa. Scripta, Belo Horizonte, v. 16, p. 151-168, 2012.

$\mathrm{KOCH}$, Ingedore Grunfeld Villaça. Introdução à Linguística Textual: trajetória e grandes temas. São Paulo: Martins Fontes, 2004.

LAHIRE, Bernard. La raison scolaire - école e pratiques d'ecriture, entre savoir et pouvoir. Rennes, FR: Presses Universitaires de Rennes, 2008.

LOURENÇO, Delane Cristina Galiza; ARAÚJO, Denise Lino de. A proposta da análise linguística/semiótica na BNCC: a natureza dos objetos de conhecimento. Eutomia, [s. l.], v. 23, n. 1, p. 88-107, 2019.

MARCUSCHI, Luiz Antônio. Cognição, linguagem e práticas interacionais. Rio de janeiro: Lucerna, 2007.

MENDONÇA, Márcia. Análise Linguística no Ensino Médio: um novo olhar, um outro objeto. In: BUNZEN, Clécio; MENDONÇA, Márcia (org.). Português no ensino médio e formação do professor. São Paulo: Parábola Editorial, 2006. p. 199-226.

NEVES, Maria Helena de Moura. Gramática na escola. São Paulo: Contexto, 1990.

NONATO, Sandoval. Escrita, ensino de língua portuguesa e formação do professor. Trabalhos em Linguística Aplicada, [s. l.], v. 58, p. 1.282-1.309, 2019a.

NONATO, Sandoval. Oralidade, ensino de língua portuguesa 
e formação do professor. Revista Brasileira de Linguística Aplicada, [s. l.], v. 19, p. 49-68, 2019 b.

PIETRI, Emerson. A constituição do discurso da mudança do ensino de língua materna no Brasil. 2003. 202 f. Tese (Doutorado em Linguística Aplicada) - Universidade Estadual de Campinas, Campinas, SP, 2003.

PIETRI, Emerson. Sobre a constituição da disciplina curricular de língua portuguesa. Revista Brasileira de Educação, [s. l.], n. 15, p. 70-83, 2010.

POSSENTI, Sírio. Por que (não) ensinar gramática na escola. Campinas: Associação de Leitura do Brasil/Mercado de Letras, 1996.

RAZZINI, Márcia de Paula Gregório. O espelho da nação: a antologia nacional e o ensino de português e de literatura (1838-1971). 2000. 442 f. Tese (Doutorado em Teoria e História Literária) - Universidade Estadual de Campinas, Campinas, SP, 2000 .

ROJO, Roxane Helena Rodrigues. Gêneros de discurso/texto como objeto de ensino de línguas: um retorno ao trivium? In: SIGNORINI, Inês, (org.). Rediscutir texto, gênero e discurso. São Paulo: Parábola Editorial, 2008. p. 73-108.

SCHNEUWLY, Bernard; DOLZ, Joaquin. (org.). Des objets enseignés en classe de français - Le travail de l'enseignant sur la rédaction de texts argumentatifs et sur la subordonnée relative. Rennes, FR: Presses Universitaires de Rennes, 2009.

SIGNORINI, Inês. Por uma teoria da desregulamentação linguística. In: BAGNO, Marcos. (org.). Linguística da norma. São Paulo: Edições Loyola, 2002. p. 93-125.

SILVA, Wagner R. Escrita do gênero relatório de estágio supervisionado na formação inicial do professor brasileiro. Revista Brasileira de Linguística Aplicada, [s. l.], v. 13, p. 171-195, 2013. 
SILVA, Wagner R.; MELO, Lívia C. de. Relatório de estágio supervisionado como gênero discursivo mediador da formação do professor de língua materna. Trabalhos em Linguística Aplicada, [s. l.], v. 47, p. 131-149, 2008.

SOARES, Magda. Português na escola - história de uma disciplina curricular. In: BAGNO, Marcos. (org.). Linguística da norma. São Paulo: Edições Loyola, 2002. p. 155-177.

SOARES, Magda. Prefácio. In: BATISTA, Antônio Augusto Gomes. Aula de português - discurso e saberes escolares. São Paulo: Martins Fontes, 1997. p. VII-XV.

TRAVAGLIA, Luiz Carlos. Gramática e interação: uma proposta para o ensino de gramática no $1^{\circ}$ e $2^{\circ}$ graus. São Paulo: Cortez, 2001.

TRAVAGLIA, Luiz Carlos. Gramática - ensino plural. São Paulo: Cortez, 2003.

TRAVAGLIA, Luiz Carlos. Que análise linguística operacionalizar no ensino de Língua Portuguesa? In: TAGLIANI, Dulce et al. (org.). Anais do II Seminário Nacional sobre Linguística e Ensino de Língua Portuguesa. Rio Grande, RS: FURG, 2010. p. 1-11. 